Boletim IG. Instituto de Geociências, USP,V. 6: 145-155, 1975

\title{
ANÁLISE DE TENDÊNCIA DE SUPERFÍCIE APLICADA À PROSPECÇĀO DE MINERAIS DE PEGMATITOS PELO MÉTODO DO CONCENTRADO DE BATEIA NA REGIĀO DE NAZARENO-CASSITERITA - MG
}

\author{
R. Francesconi,. J.V.Valarelli \\ Departamento de Mineralogia e Petrologia \\ $e$ \\ G. Amaral \\ Departamento de Paleontologia e Estratigrafia
}

\begin{abstract}
The application of trend surface analysis to mineral concentrates from pegmatites of the Nazareno-Cassiterita region disclosed a definitive pattern. The interpretation of the resulting surfaces for different minerals, indicated that the most important concentrations are located in the western portion of the region, near the Rio das Mortes, within amphibolitic rocks. Recent discoveries in that area stressed the efficiency of the trend surface technique when applied to such problems.
\end{abstract}

RESUMO

A aplicação da técnica da análise de tendência de superfície para concentrados minerais de pegmatitos da região de Nazareno-Cassiterita, mostrou um padrão definido. A interpretação das superfícies resultantes para diferentes minerais indicou que as mais importantes concentrações estão localizadas na porção oeste da região, próximo ao Rio das Mortes, encaixado em rochas anfibolíticas. Descobertas recentes nesta área reforçam a eficiência da técnica da análise de tendência de superfície quando aplicada a tais problemas.

\section{INTRODUÇÃO}

A técnica da análise de tendência de superficie tem sido cada vez mais utilizada em estudos de geologia econômica, graças à rapidez do processamento dos dados colhidos e à eliminação de critérios pessoais e subjetivos, na interpretação de variações em área, dos parâmetros desejáveis.

No Brasil, diversas tentativas foram feitas com êxito podendo ser citados trabalhos de Amaral et al (1971) e Ellert (1971) para delimitação de regiões mineralizadas nas proximidades de jazidas de níquel e de cobre, a partir de resultados analíticos de prospecção geoquímica e de dados eletro-magnéticos de prospeç̧ão geofísica, respectivamente.

No presente caso, através de dados quantitativos obtidos a partir de amostragem da fração pesada de 90 pegmatitos na região de NazarenoCassiterita, esperava-se conseguir mapas que mostrassem zonas mais favoráveis à concentração de minerais como tantalita, cassiterita, ilmenita e magnetita, pela comparação das linhas de isovalor de cada uma dessas espécies minerais, visando a obtenção de um guia indireto para futura prospecção na área estudada, ou em áreas semelhantes. 
A região escolhida para este estudo estatístico foi a das imediações da cidade de Cassiterita (fig. 1), em razão da grande densidade de afloramentos de pegmatitos existentes e pelo fato de nesta região coexistirem corpos em que a mineralização predominante é de tântalo, com outros em que o estanho é mais abundante, além de alguns estéreis.

Executou-se na região escolhida um mapeamento geológico na escala de $1: 30.000$, apresentado em 1:75.000 na figura 2 . Nessa ocasião foram locados aproximadamente 150 afloramentos de pegmatitos, alguns já conhecidos e a maioria assinalados pela primeira vez.

O Mapa Geológico da Quadrícula de Cas- siterita (fig. 2) foi executado com o objetivo de amparar a interpretação genética dos resultados da análise de tendência de superfície, procurando estabelecer controles litológicos e/ou estruturais. A geologia da área acha-se descrita em Francesconi (1972).

\section{MATERIAIS E MÉTODOS}

Amostraram-se vários pegmatitos que ocorrem em cortes de estradas, ao longo de ribeirões e córregos e outras situações, dos quais retirou-se uma porção que variou de 200 a 1000 $\mathrm{kg}$ de pegmatito alterado, dependendo da aparente concentração de pesados. Este material foi posteriormente bateado, afim de se obter o con-

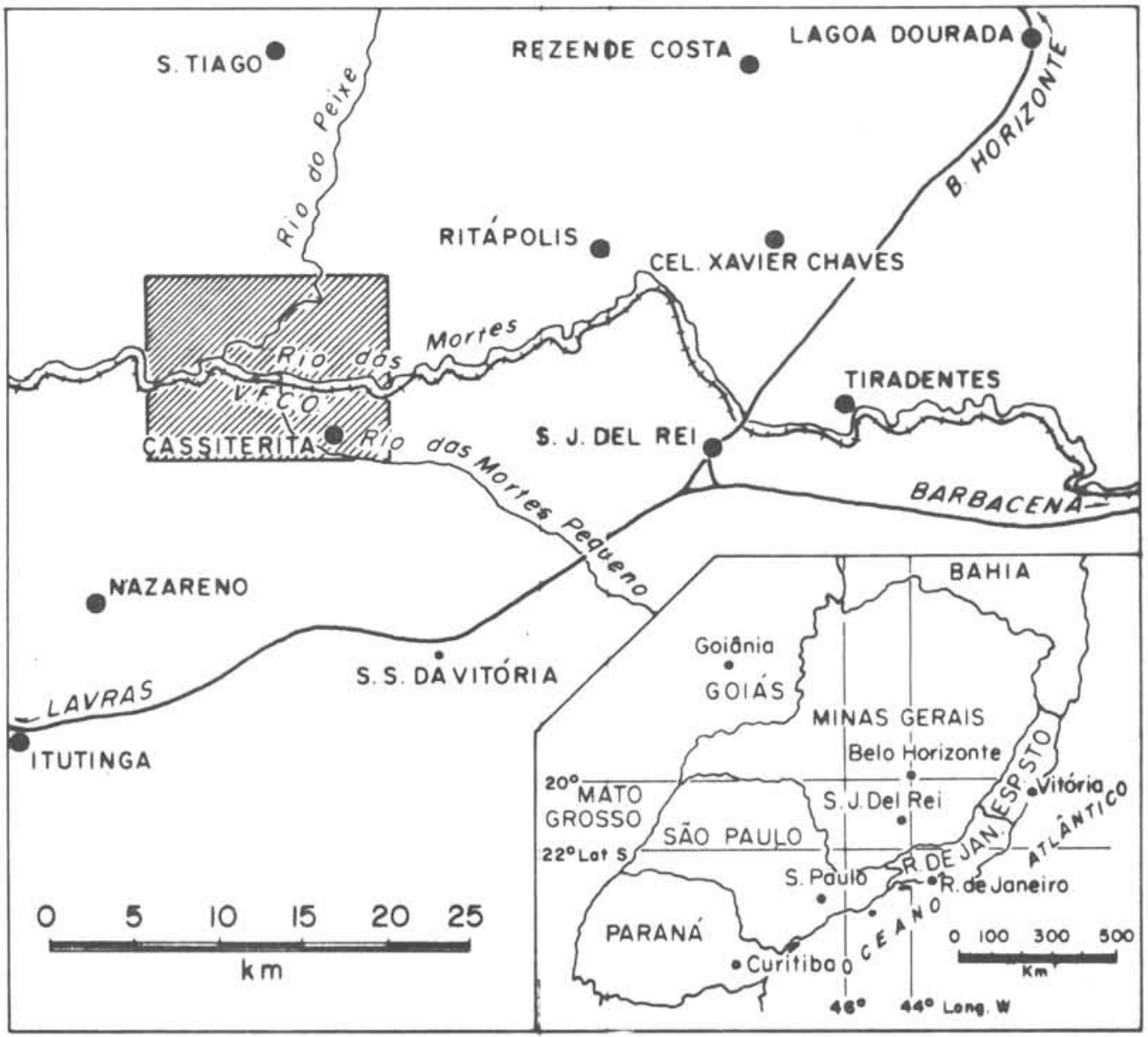

Fig. 1 - Localização da área de estudo 


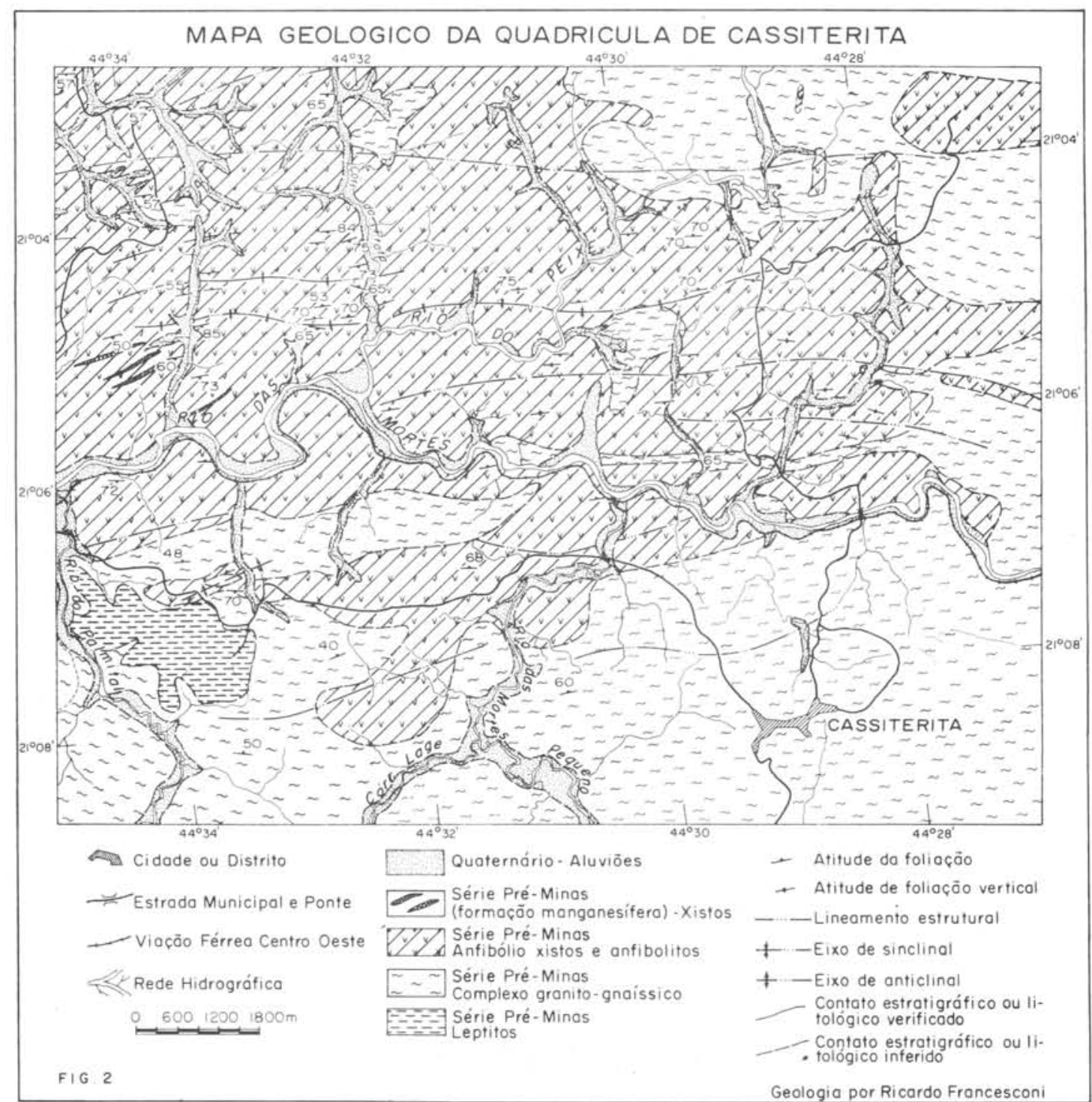

centrado pesado, conhecendo-se assim o teor deste, em gramas poŕ tonelada de pegmatito.

Em alguns casos, obtiveram-se, com sucesso, de pequena profundidade, amostras de pegmatitos retiradas a trado em locais com vestígios de pegmatitos. Esses vestígios consistem em formigueiros, nos quais se observou a presença de argila branca e plaquetas milimétricas de muscovita. Existe na região uma formiga denominada correição, que traz material de até $10 \mathrm{~m}$ de profundidade, fato esse que auxiliou bastante a prospeç̧ão de novos pegmatitos.
Em alguns destes casos, entretanto, a amostragem a trado mostrou-se inócua pelo fato da sondagem não atingir o pegmatito ou de o mesmo ser de dimensões reduzidas ou, ainda, apresentar atitude desfavorável.

As amostras de concentrados de minerais pesados foram submetidas ao seguinte processamento:

a) separação por bromofórmio;

b) separação da magnetita com imã na mão; 
c) separação eletromagnética na Usina do DNPM situada na Estação de Nazareno, que permite a obtenção das frações: magnetita-maghemita, ilmenita e tantalita-columbita;

d) separação eletrostática do resíduo anterior para obtenção das frações: cassiterita, microlita e areia quartzosa.

Após alguns ensaios preliminares para a determinação da variação das constantes elétricas e da velocidade da correia dos separadores eletromagnéticos e eletrostáticos, o tratamento dos ítens $\mathbf{c}$ e $\mathbf{d}$ adquirem uma boa reprodutibilidade, servindo de base para a avaliação econômica do pegmatito.
Para a elaboração dos cálculos foi usado o programa DTREND, desenvolvido por um dos autores (G. Amaral) para o computador Burroughs -6700 .

Este programa fornece superfície de até sexto grau, os respectivos resíduos, bem como mapas de isovalor (figs. 4 a 11) definidos por polinômios ortogonais.

Além disso o programa fornece os coeficientes de correlação e a porcentagem da soma total dos quadrados dos resíduos, que dão idéia do ajuste da superfície calculada aos dados observados.

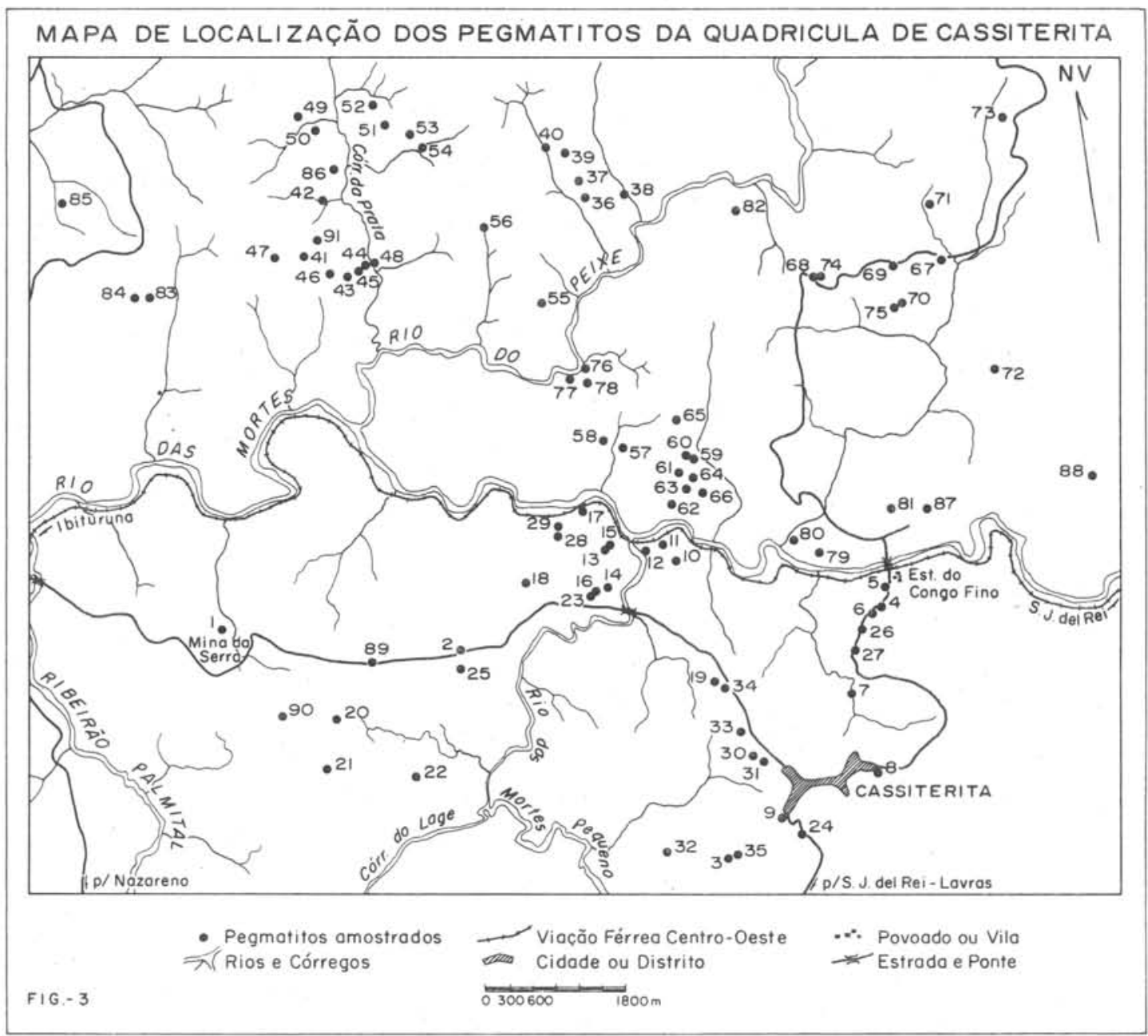


TANTALITA

SUPERFICIE DE GRAU 1

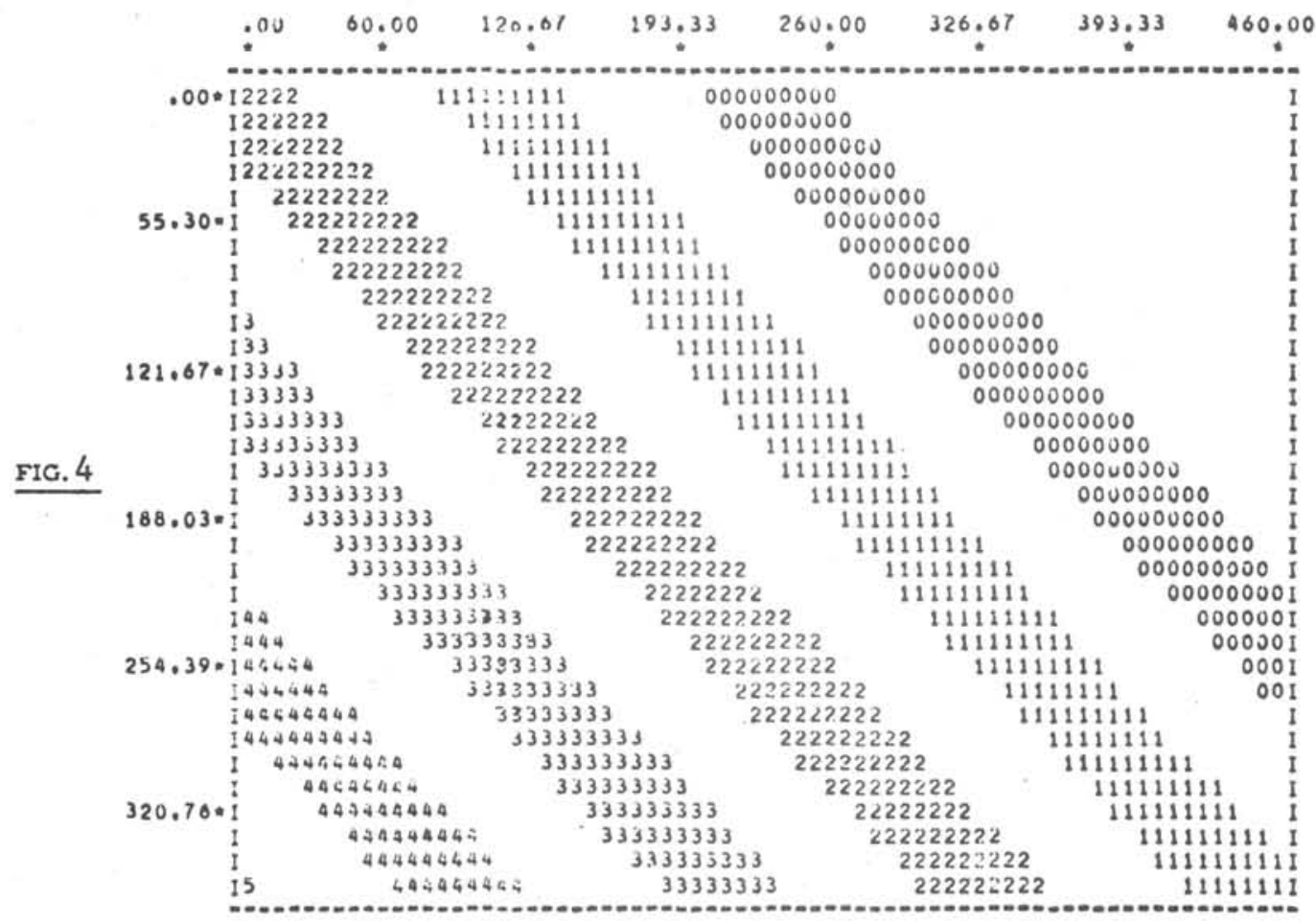

TANTALITA

SUPERFICIE. DE GRAU A

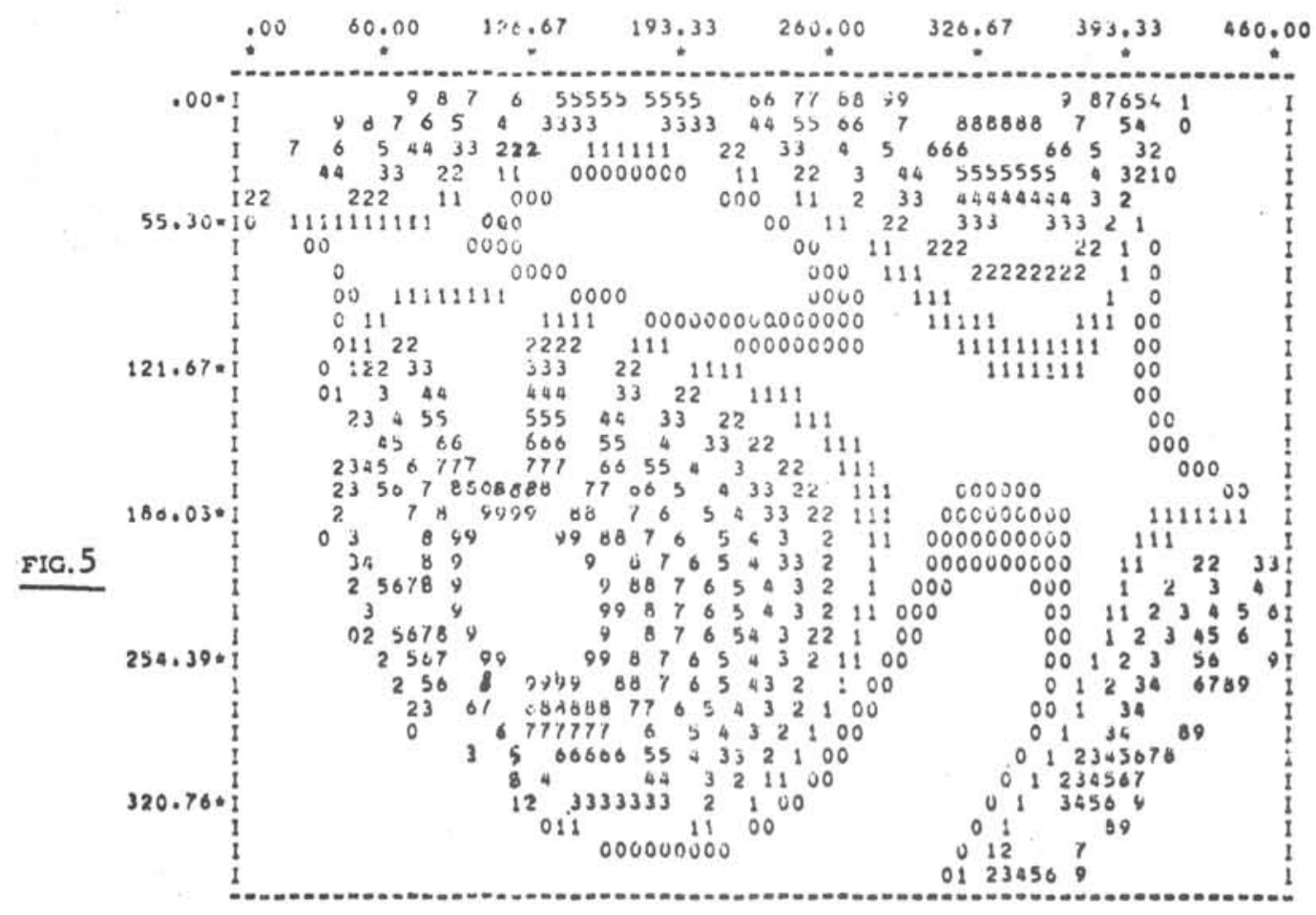


TANTALITA

SUPERFICIE DE GRAU 6

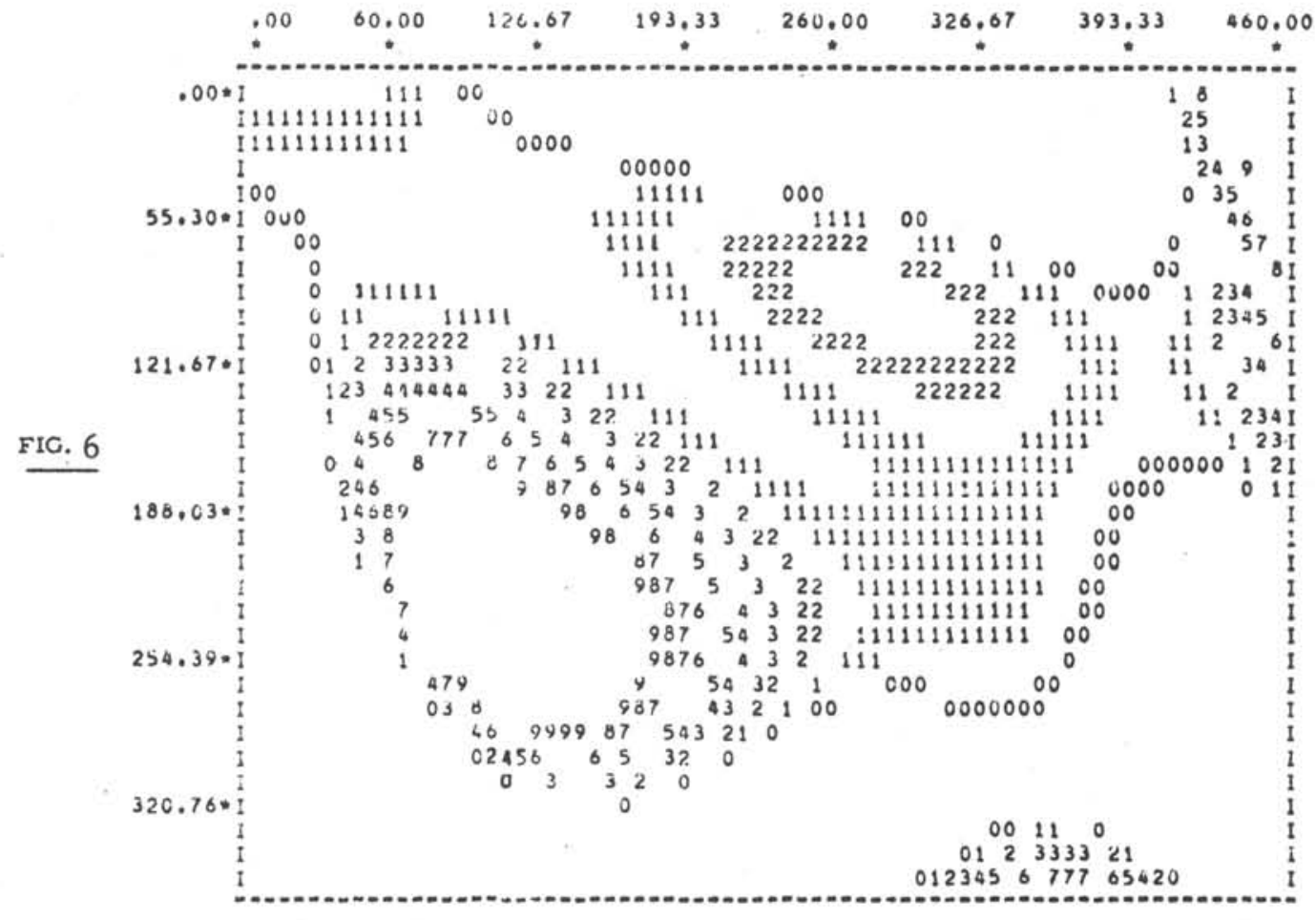

CASSITERITA

SUPERFICIE DE GRAU 1

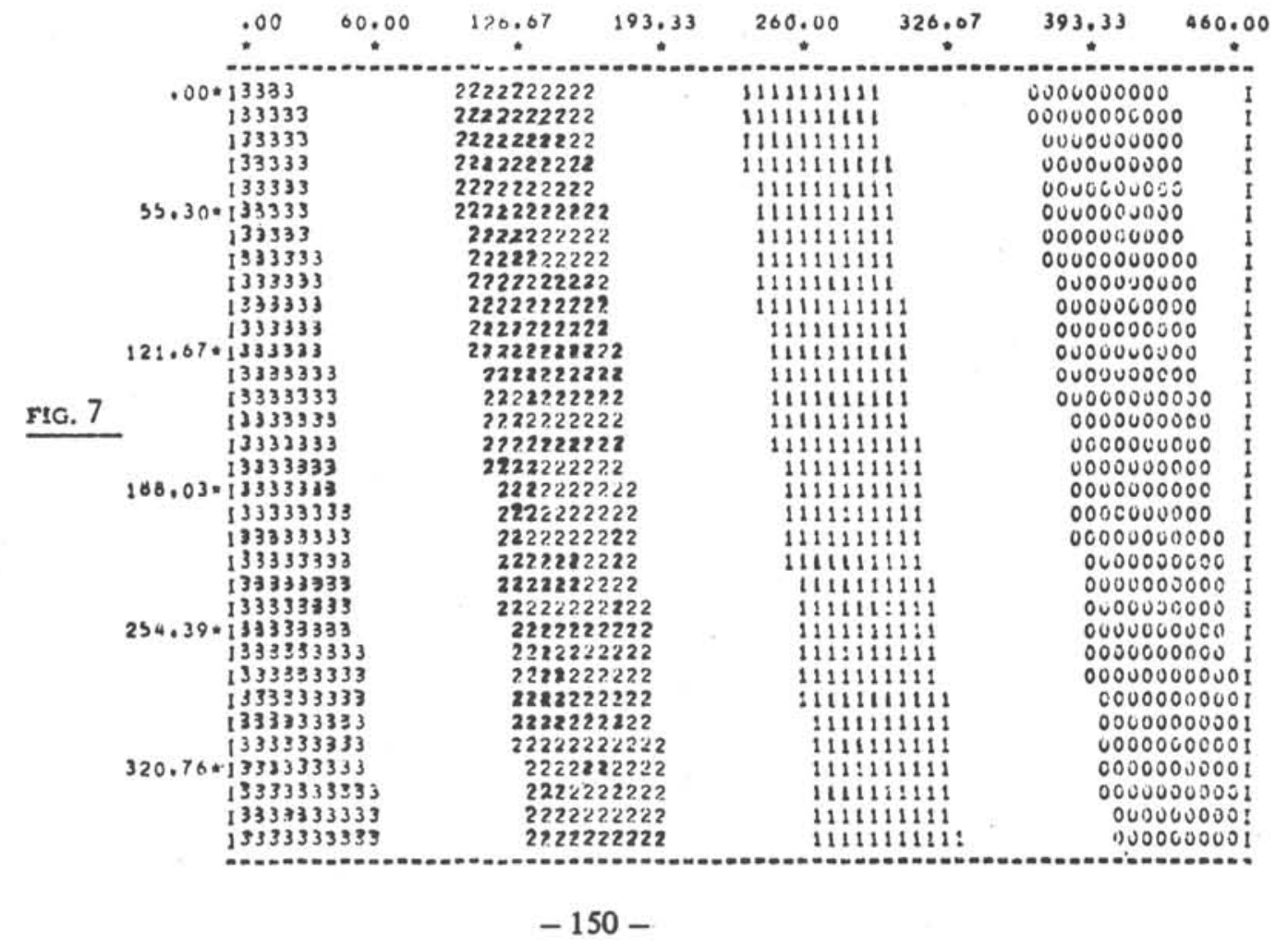


CASSITERITA

SUPERFICIE OE GRAU 3

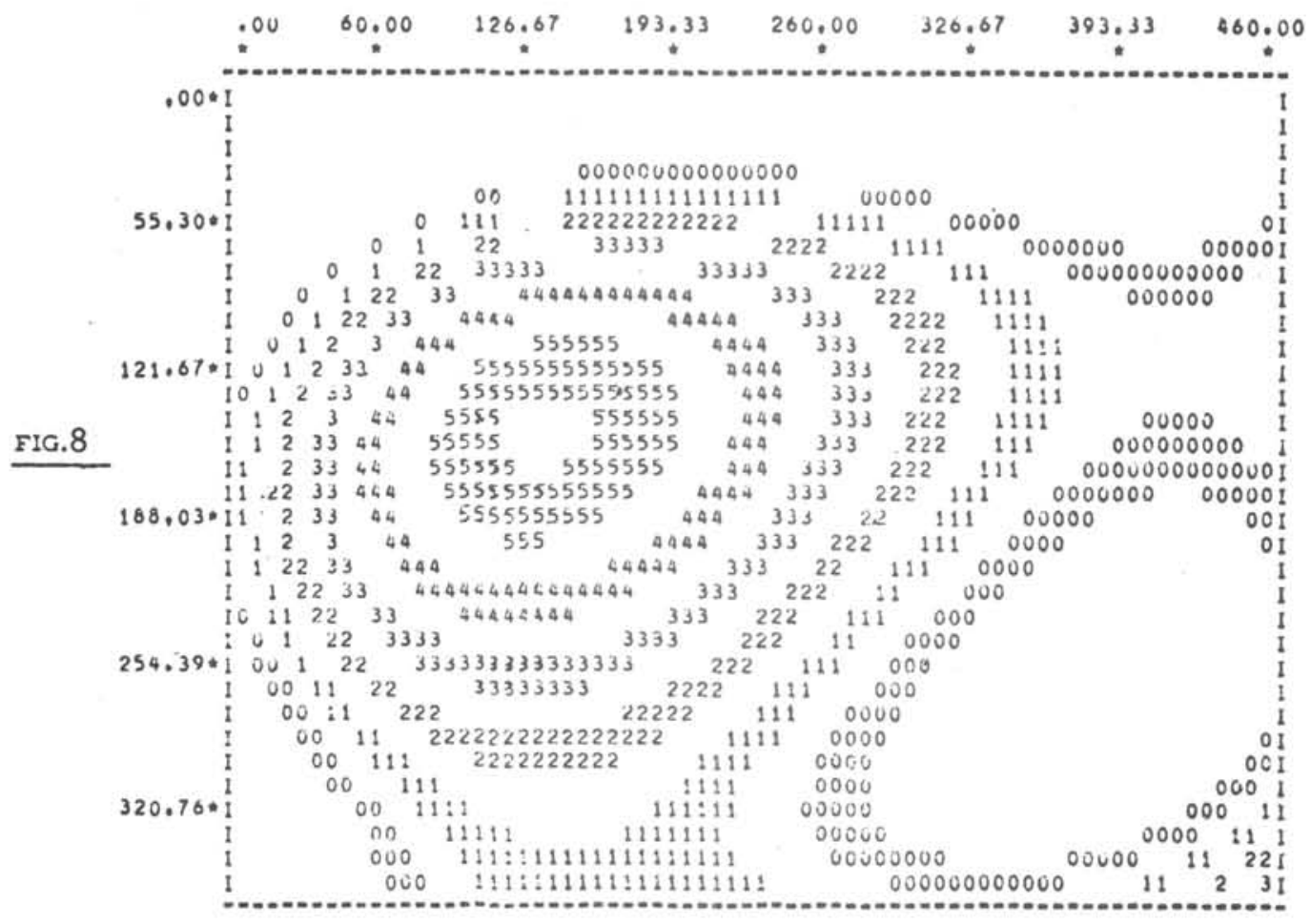

CASSITERITA

SUPERFICIL OE GRAU 6

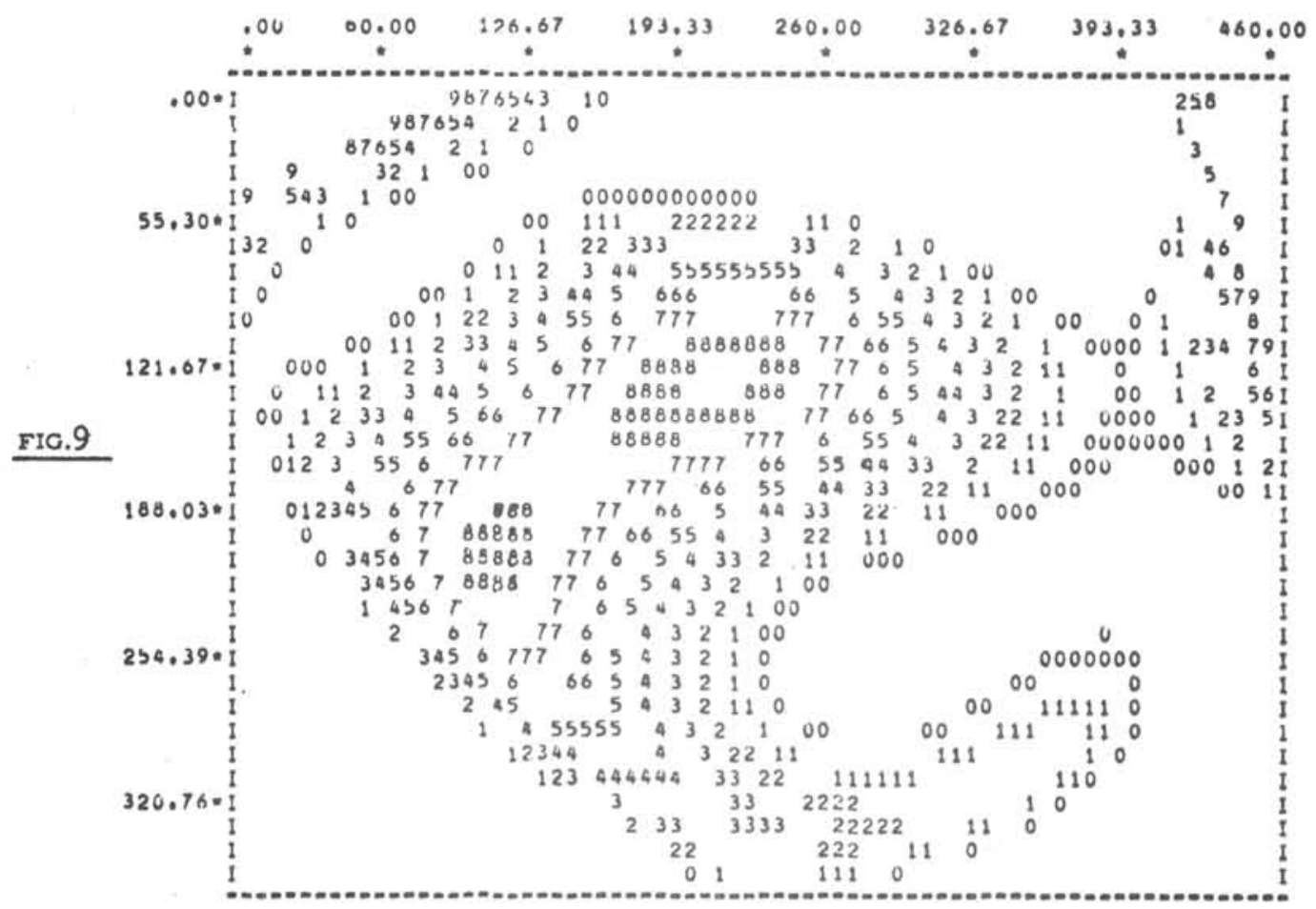


ILNENITA

SUPERFICIL DE GRAU 6

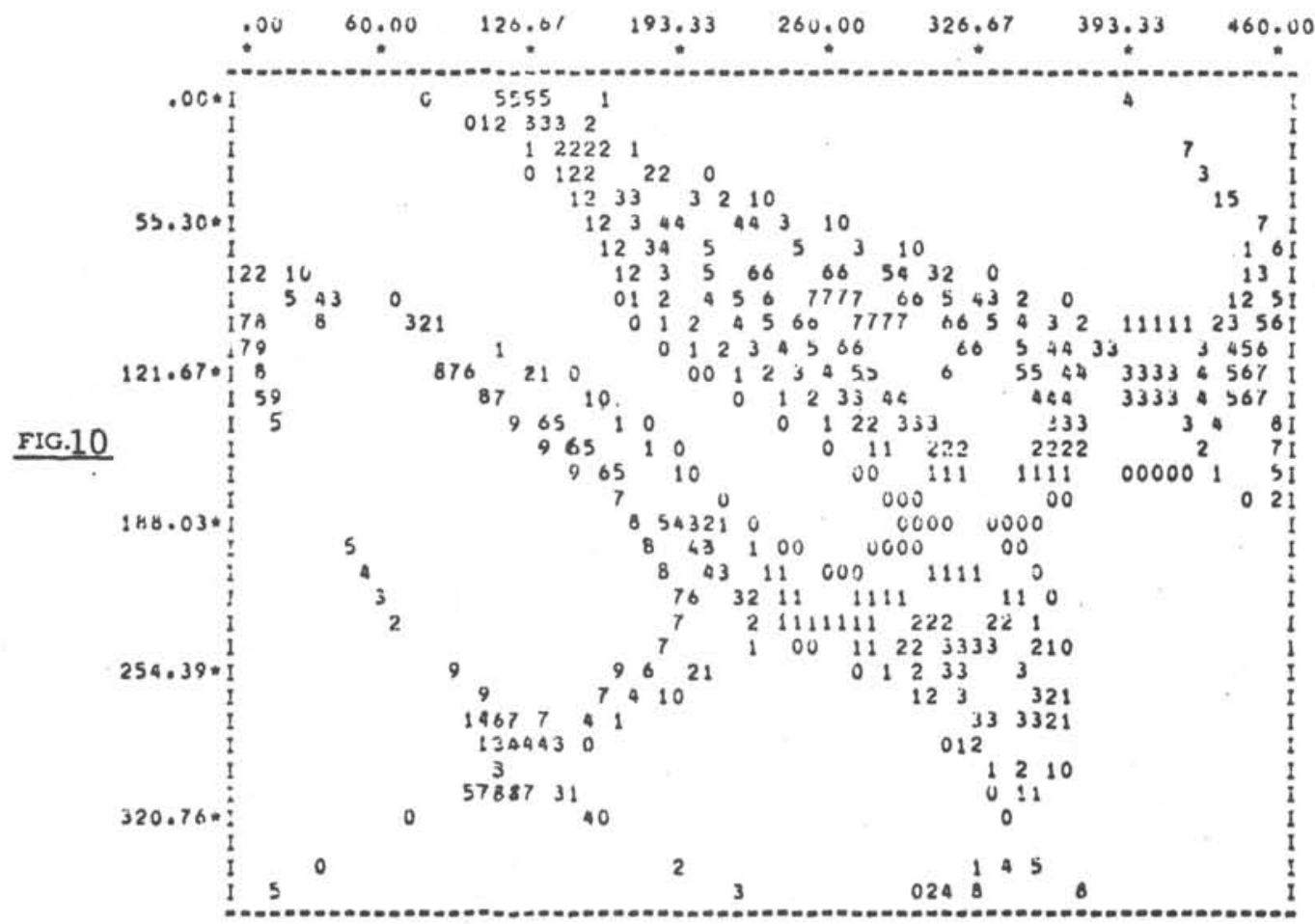

MAGVETITA

SUPERFICIE OE GRAU 6

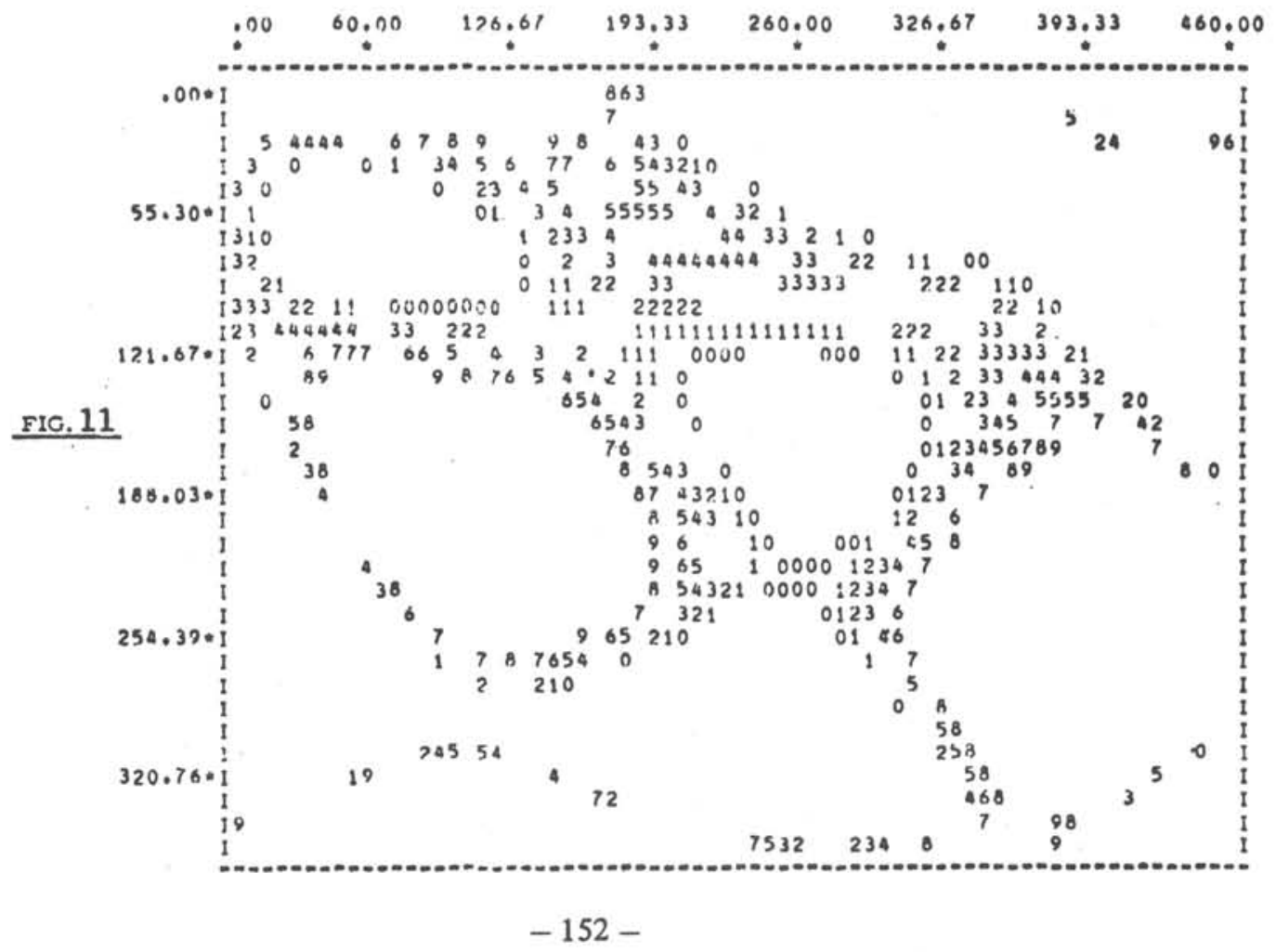


A eqüidistância usada entre as curvas foi, em primeira tentativa, de 5 ( 5 gramas de mineral por tonelada de pegmatito) e em segunda tentativa de 20, que mostrou melhor disposição gráfica.

\section{DISCUSSÃO DOS RESULTADOS}

\section{TANTALITA}

A fração denominada tantalita era constituída de minerais da série isomorfa columbitatantalita, microlita e pirocloro, além da ixiolita, que tem o mesmo comportamento no separador eletromagnético da Estação de Nazareno.

Através dos dados fornecidos pelo programa, a tantalita mostrou desde a superfície de grau 1 , tendência de crescimento segundo o sentido NE-SW (fig. 4). Na superfície de grau 4 (fig. 5) com alto coeficiente de correlação, observa-se a discriminação de um alto a sudoeste da área, que na superfície de grau 6 (fig. 6) torna-se mais evidenciado. Nesta última aparecem também zonas menos favoráveis à concentração da tantalita.

Foram colocados em mapas, na mesma escala dos executados pelo computador, os resíduos positivos ou negativos, em cada ponto amostrado.

A Tabela 2 mostra as variações das porcentagens da soma total dos quadrados dos resíduos e os coeficientes de correlação das diversas superfícies desde grau 1 até grau 6.

\section{CASSITERITA}

O processamento da fração cassiterita revelou nas superfícies de grau 1, uma distribuição crescente de E para W (fig. 7). Na superficie de grau 3, ainda que com baixo coeficiente de correlação, já se nota uma tendência de TABELA I - DADOS PARA ANALISE DE TRNDENCIA DE SUPERFICIE.
EXPRESSOS EM GRAMA DE MINERAL POR TONEIADA DE PEGMATITO.

\begin{tabular}{|c|c|c|c|c|}
\hline $\begin{array}{c}\text { Ponto } \\
\text { ne }\end{array}$ & $\begin{array}{l}\text { Tantalita } \\
\text { Columbita }\end{array}$ & Cassiterita & IImenita & Magnetita \\
\hline 1 & 480,0 & $24 A, 0$ & 0,0 & 0,0 \\
\hline 2 & A54, 5 & 301,5 & 0,0 & 0.0 \\
\hline 3 & 6,0 & 3,2 & 17,1 & 215,0 \\
\hline 4 & 62,5 & 7,5 & 64,0 & $5.993,0$ \\
\hline 5 & 12,0 & 10,0 & 14,5 & $1.153,5$ \\
\hline 6 & 18,5 & 2,5 & 5,0 & 156,0 \\
\hline 7 & 16,5 & 5,0 & 8,5 & 0,0 \\
\hline 8 & 5,5 & 1,5 & 13,0 & 11,5 \\
\hline 9 & 8,8 & 3.2 & 10,0 & 197,2 \\
\hline 10 & 11,0 & 0,4 & 2,2 & 0,6 \\
\hline 11 & 48,3 & 3,0 & 37,2 & 1,5 \\
\hline 12 & 16,4 & 1,2 & 7,6 & 2,4 \\
\hline 13 & 405,2 & 16,8 & 230,8 & 11,2 \\
\hline 14 & 19,6 & 3,6 & 0,6 & 1,2 \\
\hline 15 & 150,0 & 7,0 & 23,0 & 6,0 \\
\hline 16 & 10,6 & 0,9 & 0,7 & 0,8 \\
\hline 17 & 14,6 & 31,2 & 7,8 & 1,4 \\
\hline 18 & 70,6 & 3,5 & 5,8 & 2,8 \\
\hline 19 & 10,0 & 4,0 & 18,0 & 14,0 \\
\hline 20 & 630,6 & 333,5 & 777,0 & 6,3 \\
\hline 21 & 18,6 & 2,0 & 8,4 & 6,0 \\
\hline 22 & $A, O$ & 0,4 & 1,2 & 9.6 \\
\hline 23 & 13,6 & 9,0 & 17,2 & 1,2 \\
\hline 24 & 19,5 & 2,5 & 6,0 & 45,5 \\
\hline 25 & 64,8 & 103,8 & 5.2 & 3,4 \\
\hline 26 & 9,0 & 4,0 & 22,5 & 59,5 \\
\hline 27 & 9,5 & 2,5 & 60,0 & 193,0 \\
\hline 28 & 52,0 & 80,0 & 13,2 & 36,0 \\
\hline 29 & 49,2 & 58,8 & 32,4 & 26,4 \\
\hline 30 & 14,7 & 3,0 & 6,5 & 178,5 \\
\hline 31 & 3,3 & 1,5 & 9,3 & 1,2 \\
\hline 32 & 14,0 & 7,5 & 144,5 & 1,5 \\
\hline 33 & 3,5 & 6,0 & 12,5 & 0,0 \\
\hline 31 & 2,5 & 2,5 & 14,0 & 0,0 \\
\hline 35 & 12,0 & 5,0 & 34,0 & 970,0 \\
\hline 36 & 49,0 & 3,0 & 1,0 & 2,0 \\
\hline 37 & 16,0 & 1,0 & 13,0 & 4,0 \\
\hline 38 & 33,0 & 1,0 & 1,5 & 1,0 \\
\hline 39 & 140,0 & 5,0 & 291,0 & 119,0 \\
\hline 10 & 16,0 & 1,0 & 29,0 & 5,0 \\
\hline 41 & 69,3 & 69,7 & 27,0 & 1,7 \\
\hline 42 & 43,7 & 0,0 & 0,0 & 4,5 \\
\hline 43 & 20,7 & 15,6 & 15,7 & 10,5 \\
\hline 44 & 24,1 & 0,0 & 0,0 & 2,5 \\
\hline 45 & 0,0 & 0,0 & 0,0 & 2,6 \\
\hline 46 & 8,3 & 11,5 & 2,3 & 1,6 \\
\hline 17 & 66,5 & 407,5 & 7,1 & 0,3 \\
\hline 48 & 128,6 & 0,0 & 0,0 & 2,0 \\
\hline 19 & 12,0 & 20,0 & $2 n, 2$ & 258,0 \\
\hline 50 & 2,6 & $3, n$ & 1,5 & 12,9 \\
\hline 51 & 8,6 & 2,0 & 14,0 & 121,4 \\
\hline 32 & 4,0 & 2,4 & 6,4 & $1.000,0$ \\
\hline 53 & 10,4 & 4,4 & 15,0 & 70,0 \\
\hline 54 & 2,6 & 1,0 & 11,2 & 1,8 \\
\hline 55 & 18,9 & 619,3 & 63,2 & 20.7 \\
\hline 56 & $2 \mathrm{~N}, \mathrm{O}$ & 155,5 & 66,7 & 58,7 \\
\hline 57 & 46,4 & 115.9 & 258,3 & 63,9 \\
\hline 58 & 34,3 & 28.6 & 34,3 & 2,0 \\
\hline 59 & 59,0 & 27,5 & 7,4 & 6,0 \\
\hline 60 & 64,0 & 2,8 & 7,0 & 3,8 \\
\hline 61 & 66,2 & 7,4 & 1,4 & 21,8 \\
\hline 62 & 50,0 & 25,0 & 80,0 & 7,0 \\
\hline 63 & 65,2 & $B, B$ & 46.2 & 1,4 \\
\hline 64 & 41,2 & 4,0 & 5,5 & 7,1 \\
\hline 65 & 80.4 & 7,2 & 14.0 & 3,3 \\
\hline 66 & 99,7 & 60,0 & 33,0 & 228,7 \\
\hline 67 & 20.3 & 2,3 & 8,4 & 2,6 \\
\hline 68 & 50,0 & 1,6 & 10,0 & 0,8 \\
\hline 69 & 3,7 & 0,3 & 2,5 & 0,4 \\
\hline 70 & 61,2 & $12, \mathrm{~A}$ & 82,8 & 91,8 \\
\hline 71 & 50,4 & 1,0 & $1 \geq 0,8$ & 2,0 \\
\hline 72 & 2,3 & 1,8 & 1,3 & 0,2 \\
\hline 73 & 9,2 & 2,0 & 2,0 & 2,4 \\
\hline 74 & 60,0 & 2,4 & 12,4 & 0,2 \\
\hline 75 & 48,6 & 3,2 & $20, \mathrm{~A}$ & 9,4 \\
\hline 76 & 1ค, 8 & 288,8 & 2,4 & 1,0 \\
\hline 77 & 48,0 & 170,8 & 23,2 & 0,8 \\
\hline 78 & 53,2 & $1.628,0$ & 7,2 & $1,:$ \\
\hline 79 & 6,3 & 4,5 & 50,5 & 0,6 \\
\hline но & 3,6 & 1,6 & 19,6 & 2,4 \\
\hline 81 & 43,8 & 2,0 & 3,2 & 0,2 \\
\hline 82 & 6,0 & 2,4 & 1,2 & 2,4 \\
\hline 83 & 8,0 & 0,5 & 1,0 & 1,0 \\
\hline 84 & 15,0 & 140,0 & 10,0 & 10,0 \\
\hline 85 & 42,8 & 1,2 & 3,6 & 4,8 \\
\hline 86 & 71,2 & 13,6 & 182,4 & 920,0 \\
\hline 87 & 34,2 & 1,0 & 2,8 & 1,0 \\
\hline $8 R$ & 12.0 & 2,0 & 1,6 & 8,0 \\
\hline 89 & 104,3 & 13,7 & 3,8 & 1,6 \\
\hline 90 & 112,0 & 11,2 & 31,6 & 5,0 \\
\hline
\end{tabular}


concentração próximo ao centro da região em foco (fig. 8), sendo subdividida e mais discriminada na superfície sêxtica, em virtude do maior coeficiente de correlação encontrado (fig. 9).

O mesmo tratamento de resíduos dado à tantalita, foi aplicado no presente caso, com resultados semelhantes (Tabela 2 ).

TABELA 2

\begin{tabular}{|c|c|c|c|c|}
\hline Equidiatincta $=20$ & Tantalita & Camaiterita & Ilmenita & Magne \\
\hline \multicolumn{5}{|l|}{ Grau 1} \\
\hline S da somn dos quatradon & 9,4 & 2,0 & 1,6 & 1,9 \\
\hline coefictente de correl açio & 30,7 & 14,4 & 12,9 & 13,8 \\
\hline \multicolumn{5}{|l|}{ Grau 2} \\
\hline X da aoma don quadradon & 21,4 & 7,5 & 6,9 & 6,5 \\
\hline coeficiente de correlação & 46,3 & 27,5 & 26,3 & 25,5 \\
\hline \multicolumn{5}{|l|}{ Grau 3} \\
\hline S da aoma don quadrados & 23,9 & 11,9 & 8,5 & 10,1 \\
\hline coefic lente de correl açäo & 18,9 & 34,4 & 29,1 & $x_{1}, 8$ \\
\hline \multicolumn{5}{|l|}{ Grau 4} \\
\hline X da noma dea quadradon & 38,0 & 16,5 & 9,8 & 14,3 \\
\hline coeficlente de correlnçio & 58,0 & 391 & 30,9 & 37,9 \\
\hline \multicolumn{5}{|l|}{ Girau 5} \\
\hline S da aoma don quadradon & 46,3 & 20.4 & 11.7 & 17,5 \\
\hline coeficlente de correl nçáo & 57,1 & 44,6 & 23,2 & 40,8 \\
\hline \multicolumn{5}{|l|}{ Grau 6} \\
\hline X da aomo don quadradon & 46,8 & 22,5 & 157,4 & 19,4 \\
\hline coeficiente de correlaçio & 62,3 & so, 9 & $-10^{3}$ & 40,4 \\
\hline
\end{tabular}

\section{ILMENITA E MAGNETITA}

A finalidade do tratamento matemático para análise da distribuição desses dois minerais, foi de tentar encontrar alguma relação direta ou inversa, com tantalita ou cassiterita, o que facilitaria futuras prospecções e pesquisas na área.

Desde a superfície de grau 1, ambas frações mostraram porcentagem de soma total dos quadrados dos resíduos e coeficientes de correlação muito baixos, exceção feita à superfície de 69 grau da ilmenita (fig. 10) que apresentou alta porcentagem dessa soma, mas coeficiente de correlação negativo (indeterminado) (Tabela 2).

Ficou demonstrado que não existe tendência para a distribuição de ilmenita, sendo a mesma aleatória.

Quanto à magnetita, parece haver uma leve tendência de configuração semelhante à da tantalita (fig. 11), porém, apresentando baixo coeficiente de correlação (Tabela 2).

\section{CONCLUSÕES}

As observações resultantes da análise de tendência de superfície comparadas com o mapa geológico da quadrícula de Cassiterita (fig. 2) fazem supor que um dos focos de fluídos pegmatíticos se encontra na região sudoeste daquela quadrícula, próximo ou adjacente aos leptitos.

As linhas isoteores do trend não distinguem, aparentemente, as litologias das encai xantes, pela ponderação dos teores. No entanto pelos dados constantes da Tabela 1, verifica-se que os afloramentos situados nos anfibólio xistos, ou mesmo no contacto destes com os gnaisses, são os maiores responsáveis pela tendência de concentração de $\mathrm{Ta}$ e $\mathrm{Nb}$ e por duas abas de concentração de $\mathrm{Sn}$.

A figura 9 (trend de 6.0 grau de cassiteri$t a)$ mostra uma disposição simétrica em relação a uma fonte, apresentando suas maiores concentrações em duas abas opostas e mais externas, em relação à distribuíção da tantalita.

Tais relações permitem supor que, pelo menos localmente, as soluções mineralizantes de $\mathrm{Ta}-\mathrm{Nb}$ e as de $\mathrm{Sn}$ provém da mesma fonte, embora difiram quanto às distâncias e formato das zonas nas quais agiram de modo mais acentuado e, por analogia, quanto ao predomínio da etapa de evolução do processo pegmatítico. 
Os coeficientes de correlação relativamente baixos apresentados pelas análises de trend de magnetita (Tabela 2), talvez possam ser explicados por problemas de separação, de liberação ou de martitização. Porém, para a sua disposição na superfície de 6 ? grau (fig. 11), parece haver um motivo geológico.

A magnetita deve ter sido formada nos estágios magmáticos iniciais dos pegmatitos. A mineralização tântalo-niobífera, que com a evolução passou a ser niobo-tantalífera, se deu predominantemente nos primeiros estágios pneumatolíticos (K e Li) (Ginsbourg, 1960). A cassiterita teve seu desenvolvimento maior na fase $\mathrm{Na}$, posterior as anteriores, e provavelmente, após algum tectonismo.

Pesquisas recentes (1973-1974), efetuadas pela Cia de Estanho São João Del Rey e outras, comprovaram a existência de alguns corpos com alto conteúdo de minerais tântalos-niobíferos e estaníferos exatamente nas porções em que as superfícies de grau 6 de tantalita e cassiterita apresentam altos, ou seja, na parte centro-sudoeste da quadrícula. Esse fato vem comprovar os resultados apresentados neste trabalho, reforçando a validade do procedimento.

\section{BIBLIOGRAFIA}

AMARAL, G. e ELLERT, N. (1971) - Aplicação do trend suface analysis a interpretação do levantamento geoquímico e geofísico da jazida de níquel de Ipanema, Minas Gerais. XXV Congr. Bras. Geol., São Paulo, Res. Comunicações, p. 114.

FRANCESCONI, R. (1972) - Pegmatitos da Região de São João Del Rei, MG. Tese apresentada ao Instituto de GeociênciasUSP. $101 \mathrm{pg}$.
ELLERT, N. (1971) - Aplicação do método eletro-magnético indutivo na prospecção de minério de cobre. Tese apresentada ao Instituto de Geociências-USP (inédita).

GINSBOURG, A.I. (1960) - Specific geochemical feature of the pegmatitic process. XXI Int. Geol. Congr. Part. XVII p. 111. 